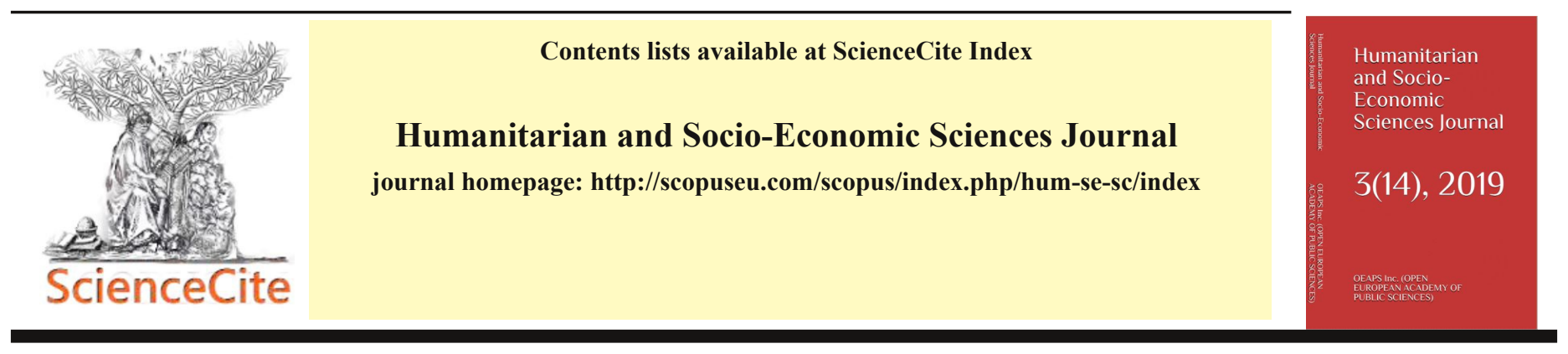

Talking about Sexual Attitudes and Behaviors; a Cultural and Social Taboo in Afghanistan

\title{
Hamidullah Bamik*
}

Fulbright Scholar and Graduate Student in Educational Leadership and Policy Analysis, Department of Educational Leadership and Policy Analysis, College of Education, University of Missouri-Columbia, USA

\section{ARTICLE INFO ABSTRACT}

\section{Article history:}

Received

Mar/01/2019

Accepted Mar/05/2019

Available online Mar/14/2019

\section{Keywords:}

Sexual Attitudes and

Behaviors of Afghans,

Sex Education,

Sexual Relationship,

Public Dominant Views on

Sexual Issues,

Cultural and Social

Impacts on Sexual Issues

Interpretations
As per the latest survey of the Afghan Institute for Strategic Studies on sexual attitudes and behaviors of Afghan youths, most Afghan teens and adolescents do not have information about the healthy sexual relationship. 90 percent of those interviewed in the survey said that there is a pressing need for sex education in Afghanistan. Although the new generation of Afghanistan, despite close and strict traditions, have been able to create opportunities for themselves to talk about various social and cultural topics so as to understand better their opposite sex's characteristics before entering an official relationship - marriage life, still talking about sexual attitudes and behaviors in public and families remains as a cultural and social taboo in Afghanistan. Likewise, the purpose of this paper is, first, to discuss the dominant views among the people on sexual relationship and issues in Afghanistan. Second, to analyze the cultural and social barriers that lead to lack of debating on sexual attitudes and behaviors among families and youths in the society. And finally, to present recommendations for promoting sex education at schools, and encouraging families and parents to talk with their children about the sexual issues and look at them as a natural phenomenon, not as a cultural and social taboo.

(C) 2019 The Author. Published by OEAPS Inc.

This is an open access article under the CC BY-NC-ND license (http://creativecommons.org/licenses/by-nc-nd/4.0/).

* Corresponding author.E-mail address:
hamidullahbamik@mail.missouri.edu
Crossref DOI:

EU Sciences Cataloge DOI: 10.5281/zenodo.2619861

ISBN: 9781090370884 


\section{INTRODUCTION}

One of the most important components of marital life is having a healthy and satisfying sexual relationship of couples. Regarding the importance of family in Afghan society and the role of couples' sexual health in maintaining family's continuation and preventing marital problems, attention to promoting sexual health is important in different levels of individual and social life. Addressing issues such as sex education for couples getting married, sexually transmitted infections (STIs) education and prevention, counseling and treatment of sexual dysfunction and abnormalities in sexual behavior and the prevention of sexual high-risk behaviors, preventative abuses, and sexual violence are highly important in the society. It should be noted that sexual health is not only unique in terms of fertility, but health is important from infancy and birth to death for men and women. To put it simply, at all stages of life, it is important to address the different aspects of sexual health because lack of attention in this regard may have adverse effects on youth's behaviors, later in their lives.

In June 2018, Afghan Institute for Strategic Studies (2018) published its latest survey entitled "Transition to Adulthood; Sexual Attitudes and Behaviors of Youth in Afghanistan." The survey has been conducted in a conversation with 1,350 people aged 15 to 34 in the 10 largest provinces of Afghanistan. Sediqa Bakhtiari, one of the researchers (2018), articulates that in the survey, the attitude and sexual behavior of youth and adolescents after childhood have been examined. This study echoes that most Afghan youths do not have information about healthy sexual relationship. In this survey, $36 \%$ of the interviewees had no information about AIDS, and only $20 \%$ were familiar with safe and healthy relationships. And, 90 percent of those interviewed in this study said that there is a pressing need for sex education in Afghanistan.
The research shows that ignoring the debate on sexual issues has led Afghan young people to go to other sources for obtaining information about sexual matters that do not provide the right information to them. For example, according to this study, 60 percent of Afghan youths use sexy content such as movies and photos to address their sexual instinct. The researchers of this survey argue that using such objects for tackling sexual needs can have personal and social damage. Its personal damage includes imitation of patterns of misconception, depression, and frustration, mental disorders, and addiction to such content and social damages are encouraging the youth toward committing rape, violence, street harassment and, in some cases, avoidance of marriage (Afghan Institute for Strategic Studies, 2018).

Studies project that widespread rape, honor killings, sexual violence, and child abuse in Afghanistan are the malicious results of lack of information and public awareness about sexual attitudes and behaviors (Afghanistan Independent Human Rights Commission, June 20, 2018; Shayegan, 2014). According to Ruhollah Amin, a psychologist in Afghanistan (June 29, 2018), talking about sexual needs and issues has a very negative connotation in Afghan society. He argues that even among couples, talking about a sexual relationship is interpreted as bad, embarrassing, and heinous and should be kept secret. In his opinion, this social and cultural censorship has become a kind of self-censorship that causes disorders for a person, and finally, the consequences of such self-censorship rise in other ways that are inconsistent with the cultural and social norms of the society. For instance, jokes and poems that have sexual content and violence are indicative of such cultural censorship in society (BBC, June 30, 2018). He emphasizes the need for a social and cultural campaign in Afghanistan regarding sexual attitudes and behaviors so that individuals can become aware of their sexual needs legally as a human. 
The current paper aims to discuss the common behaviors and attitudes of people, youths, and families toward sexual issues, sex education, and sexual relationship between the opposite sexes. And finally, this paper ends with presenting recommendations for promoting sex education at schools and encouraging families and parents to talk with their children about the sexual issues and look at them as a natural phenomenon, not as a cultural and social taboo.

\section{RESEARCH QUESTIONS}

What are the predominant sexual attitudes and behaviors among the youths in Afghanistan?

Why do people consider talking about sexual attitudes in Afghanistan as a cultural and social taboo?

What are the possible solutions for tackling this issue?

\section{METHODOLOGY}

For conducting this research, the author has used a qualitative method and desk study. The information for the current study is collected from reliable sources such as UNICEF, UNESCO, World Bank reports, Afghan Institute for Strategic Studies surveys, peerreviewed articles, reports, and articles published by leading national and international news agencies, and numerous other genuine sources.

\section{LITERATURE REVIEW}

Sexual Issues and their Interpretation in Afghanistan's Social and Cultural Context

As Afghanistan is a traditional country and at the same time has religious people who strongly believe in the traditional Islamic and religious principles, talking about sexual issues is a taboo (Niazi, Oct. 30, 2016).

Chart 1: Attitude toward touching and sexual relationship with the opposite sex $(\%)$

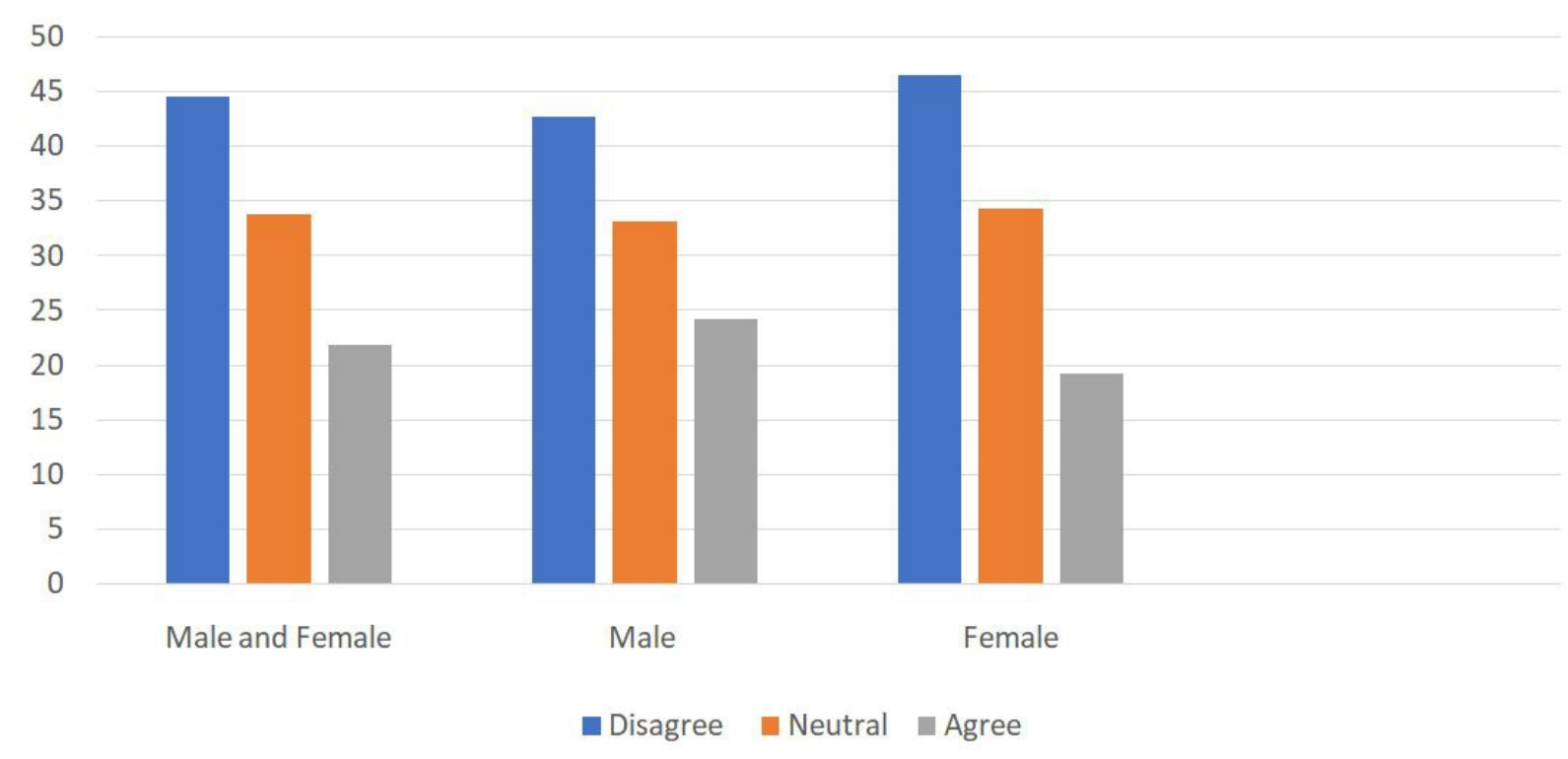

Source: Afghan Institute for Strategic Studies; Transition to adulthood; sexual attitudes and behaviors of youth in Afghanistan (June 2018) 
As Chart 1 shows, 33\% of the people surveyed had negative attitudes (opposing) about the physical and sexual relationship with the opposite sex outside the marital domain, while $22 \%$ had a positive attitude (agree) with this type of relationship, and 33\% had neutral views. Therefore, the negative attitude toward these relationships was twice as positive. Positive attitude toward sexual relationship among men (23\%) was more than women (12\%). The findings of the Afghan Institute for Strategic Studies survey (2018) indicate that with increasing education level, positive attitude toward a physical and sexual relationship with the opposite sex is also increasing. For example, people with religious education had 2 percent positive attitudes and illiterate people had a positive attitude of $23 \%$ with this type of relationship. In comparison, this proportion was 34\% for those with master's degrees and doctorate degrees.
The findings of the Afghan Institute for Strategic Studies Survey (2018) demonstrate that a very small percentage of women surveyed said that they had sexual relations with the opposite sex in their lives before marriage. And, they are very careful in friendship with the opposite sex and try not to have advanced sexual relationship (sexual intercourse). This behavior is originated from Afghan culture and traditions and the importance of girls' virginity for marriage (Afghan Institute for Strategic Studies Survey, June 2018). 3/4 of the young people in Afghanistan believe that girls' virginity is a precondition for marriage with them. The proportion of agreeing to this cultural norm for boys is $83 \%$ and for girls, it is $33 \%$ (Afghan Institute for Strategic Studies Survey, June 2018).

Chart 2: The view of the youth surveyed on girls' virginity as a precondition for marriage $(n=1311)(\%)$

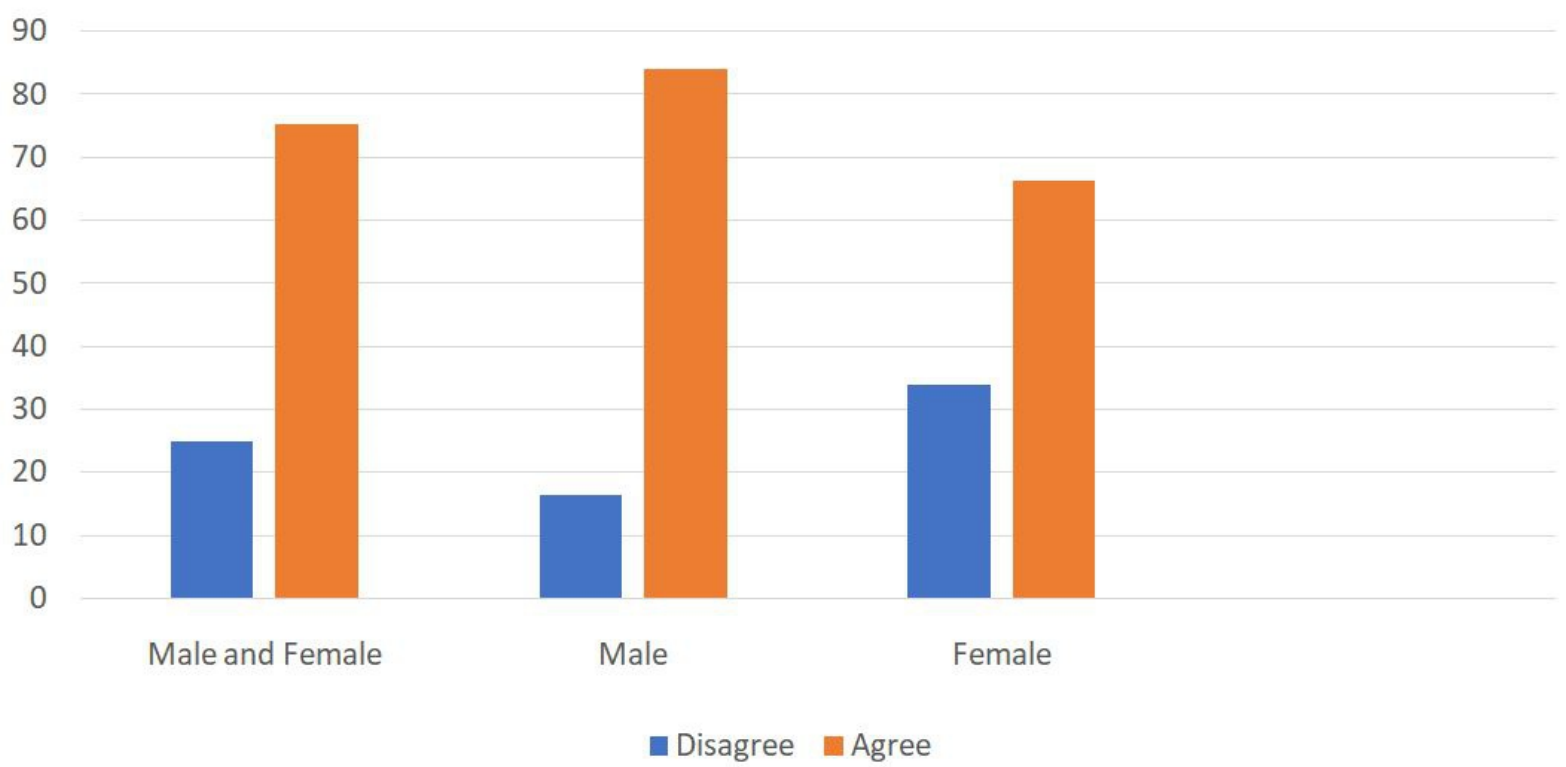

Source: Afghan Institute for Strategic Studies; Transition to adulthood; sexual attitudes and behaviors of youth in Afghanistan (June 2018) 
The findings of the Afghan Institute for Strategic Studies Survey (2018) emphasize on the personal and social importance of virginity in the Afghan community. The authors argue that in a qualitative study, all participants referred to the social importance of virginity for women before marriage. They believe that society expects women to preserve their bodies as a trust for their future spouses. Regardless of the fact that some girls don't have hymen naturally or it is broken due to physical activities such as physical exercising (Marturana,
Oct. 26, 2016), in a traditional society like Afghanistan, girls are highly expected to have virginity before marriage. Because not having the hymen, is considered immoral and adultery. Therefore, the precondition for marriage with girls is having virginity. Sometimes the absence of a hymen threatens the human personality of a woman. As a result, the same cultural and social glance that would slam her human values would justify her punishment and even her murdering (Afghan Institute for Strategic Studies Survey, June 2018).

Table 1. Public awareness regarding a healthy sexual relationship among people surveyed (\%)

\begin{tabular}{|c|c|c|c|c|}
\hline \multirow{4}{*}{$\begin{array}{l}\text { Do you have information } \\
\text { about the transmission of } \\
\text { HIV (HIV) through an } \\
\text { unhealthy sexual } \\
\text { relationship? }\end{array}$} & & Male and Female & Male & Female \\
\hline & No & 35.7 & 34.7 & 36.7 \\
\hline & Yes & 64.3 & 65.3 & 63.3 \\
\hline & Number of Samples & 1350 & 685 & 665 \\
\hline \multirow{12}{*}{$\begin{array}{l}\text { If yes, the sources } \\
\text { obtaining information } \\
\text { regarding AIDS (HIV) }\end{array}$} & TV & 23.2 & 23.1 & 23.5 \\
\hline & Satellite & 18.6 & 19.0 & 18.1 \\
\hline & Internet & 11.6 & 12.4 & 10.7 \\
\hline & Friends & 10.5 & 11.8 & 9.0 \\
\hline & Teachers & 9.2 & 6.6 & 12.2 \\
\hline & Personal study & 8.2 & 6.3 & 10.4 \\
\hline & Radio & 4.2 & 6.8 & 1.1 \\
\hline & $\begin{array}{l}\text { Educational } \\
\text { Workshops }\end{array}$ & 3.4 & 2.6 & 5.1 \\
\hline & Health Clinics & 3.1 & 4.2 & 1.7 \\
\hline & Family & 1.3 & 1.0 & 1.7 \\
\hline & Others, not stated & 6.3 & 6.2 & 6.5 \\
\hline & Number of Samples & 868 & 447 & 421 \\
\hline \multirow{3}{*}{$\begin{array}{l}\text { Do you know, what } \\
\text { methods to use for having } \\
\text { a healthy and safe sexual } \\
\text { relationship? }\end{array}$} & No & 80.1 & 74.9 & 85.4 \\
\hline & Yes & 19.9 & 25.1 & 14.6 \\
\hline & Number of Samples & 1350 & 685 & 665 \\
\hline \multirow{4}{*}{$\begin{array}{l}\text { If yes, from what method } \\
\text { do you use for having a } \\
\text { healthy sexual } \\
\text { relationship? }\end{array}$} & Condom & 73.1 & 74.5 & 70.7 \\
\hline & Contraceptive pills & 21.7 & 21.7 & 21.7 \\
\hline & Anal Sex & 3.2 & 3.2 & 3.3 \\
\hline & $\begin{array}{l}\text { Having } \\
\text { confidence/trust in the } \\
\text { healthiness of the } \\
\text { opposite sex }\end{array}$ & 2.1 & 0.6 & 4.3 \\
\hline Number of Samples & & 269 & 172 & 97 \\
\hline
\end{tabular}


Source: Afghan Institute for Strategic Studies; Transition to adulthood; sexual attitudes and behaviors of youth in Afghanistan (June 2018)

The above table projects that $33 \%$ of the sample was aware of the transmission of HIV through an unhealthy sexual relationship. Also, $21 \%$ were aware of the prevention method used to have a healthy sexual relationship. The results also show that people who use social network and media have a greater awareness of the healthy sexual relationship. In addition, the findings of this study demonstrate that those who have already a sexual relationship experience are significantly more likely to have a healthy sexual relationship than those who don't. The authors of the survey argue that having awareness about a healthy sexual relationship has been greater among those belonging to families with higher levels of education and income and high socioeconomic status.

In addition, the findings of this survey show that 34 $\%$ of people surveyed seek information about their sexually explicit issues sometimes or always via the Internet. This ratio was $33 \%$ for men and $28 \%$ for women. In the context of the need for young people to engage in premarital sex education, the findings show that $11 \%$ of the participants said there is no need for education at all; $33 \%$ said there is a need for sex education at a low level, $22 \%$ felt somewhat less likely to need sex education for young people. Finally, one-third of the respondents (33\%) said that premarital sex education is very important for young people, which is a high need for girls (38\%) and boys $(28 \%)$.

Table 2 indicates that "Internet resources and friends," were the most frequent used sources among the people surveyed for finding information regarding the sexual relationship. However, both of these two sources were more common among men than women. On the contrary, women speak with their parents, in particular, their mother, about sexual transition more than men. Also, girls are more likely to consult with their sisters and boys with their brothers about sexual relationships (Table 2). It indicates that both sexes are using different methods for seeking information to understand their sexual transition. As a rule, boys are more likely to receive their sexual information and understanding from friends and outsiders, while girls are more likely to receive relatively high rates of sexual education from their mothers. In general, the Afghan parents' contribution to the education of their children regarding sex is very scant and sometimes they give no information to their progenies in this regard (Afghan Institute for Strategic Studies Survey, June 2018).

As a result, talking about the sexual relationship between parents and children is a social taboo. On the one hand, this lack of discussion is due to shame and the psychological and social distance between parents and children. On the other hand, some parents believe that with this kind of education, they will somehow provide the possibility of their children's sexual depravity. Hence, parents often or at all don't talk to their children about sexual issues (Afghan Institute for Strategic Studies Survey, June 2018).

\section{Lack of Sex Education at Afghan Schools}

Afghanistan is a traditional country and its people are religious who strongly believe in the traditional Islamic and religious principles. The contents and subjects of the school curriculum in Afghanistan are also designed based on these Islamic principles and traditional values of the people (Compilation \& Translation, 2003). In 2016, the city of Kabul witnessed a public campaign that broke many of the taboos and traditions in the country. This campaign was specifically talking about sexual attitudes and behaviors of youths and the problems and inadequacies surrounding them in Afghanistan 
Table 2. People's views on sex education, and resources used for understanding sexual issues (\%)

\begin{tabular}{|c|c|c|c|c|}
\hline & & Male and Female & Male & Female \\
\hline \multirow{8}{*}{$\begin{array}{l}\text { Sources for obtaining } \\
\text { information about sexual } \\
\text { issues }\end{array}$} & Mother & 12.8 & 3.0 & 22.2 \\
\hline & Father & 1.4 & 2.6 & 0.2 \\
\hline & Brother & 1.3 & 2.2 & 0.4 \\
\hline & Sister & 3.5 & 0.9 & 6.0 \\
\hline & Friends & 38.4 & 43.5 & 33.5 \\
\hline & Teachers & 5.9 & 6.5 & 5.3 \\
\hline & Internet & 30.9 & 36.0 & 26.0 \\
\hline & Others (i.e. books) & 5.8 & 5.3 & 6.4 \\
\hline \multirow{5}{*}{$\begin{array}{l}\text { Sharing sexual issues } \\
\text { with parents }\end{array}$} & Never & 55.9 & 63.6 & 47.8 \\
\hline & Rarely & 21.2 & 19.1 & 23.3 \\
\hline & Sometimes & 14.1 & 12.0 & 16.2 \\
\hline & Often & 4.0 & 2.5 & 5.6 \\
\hline & Always & 4.9 & 2.8 & 7.1 \\
\hline \multirow{2}{*}{$\begin{array}{l}\text { The perfect time to talk } \\
\text { to families about sexual }\end{array}$} & After maturity & 43.9 & 41.6 & 46.2 \\
\hline & $\begin{array}{l}\text { During engagement } \\
\text { period }\end{array}$ & 38.6 & 41.2 & 35.9 \\
\hline $\begin{array}{l}\text { issues and marital } \\
\text { relationships }\end{array}$ & Wedding night & 17.6 & 17.2 & 17.9 \\
\hline \multirow{3}{*}{$\begin{array}{l}\text { Does your family talk to } \\
\text { you about the sexual and } \\
\text { marital relationship on } \\
\text { the day of the wedding? }\end{array}$} & I don't think they do & 37.5 & 47.7 & 26.9 \\
\hline & $\begin{array}{l}\text { Yes, probably they } \\
\text { do }\end{array}$ & 41.6 & 36.2 & 47.1 \\
\hline & Yes, surely, they do & 21.0 & 16.1 & 26.0 \\
\hline \multirow{5}{*}{$\begin{array}{l}\text { Seeking information } \\
\text { regarding sexual issues } \\
\text { and relationship via the } \\
\text { internet }\end{array}$} & Never & 40.5 & 32.5 & 49.0 \\
\hline & Rarely & 22.1 & 21.7 & 22.7 \\
\hline & Sometimes & 25.9 & 32.0 & 19.7 \\
\hline & Often & 7.6 & 9.5 & 5.7 \\
\hline & Always & 3.9 & 4.8 & 2.9 \\
\hline \multirow{4}{*}{$\begin{array}{l}\text { The percentage of need } \\
\text { for young people to have } \\
\text { sex education before } \\
\text { marriage }\end{array}$} & There is no need & 11.3 & 10.8 & 11.9 \\
\hline & Little & 33.5 & 36.3 & 3.7 \\
\hline & To some extent & 22.4 & 25.0 & 19.8 \\
\hline & More & 32.7 & 27.9 & 37.6 \\
\hline \multicolumn{2}{|c|}{ Number of Samples } & 1350 & 685 & 665 \\
\hline
\end{tabular}

Source: Afghan Institute for Strategic Studies; Transition to adulthood; sexual attitudes and behaviors of youth in Afghanistan (June 2018) 
(Horizon News Agency, Oct. 23, 2017). Holding such public awareness programs are very pivotal and vital in this regard but not adequate. Because, first, such campaigns only take place out of schools by private organizations in Afghanistan. Second, these kinds of social and cultural public awareness programs occur in big cities of Afghanistan where far-reaching provinces are not witnessing such campaigns. Third, schools that are considered to be the main training centers for children don't have any clear and specific programs regarding educating the students about their sexual attitudes and behaviors, unfortunately.

Afghanistan's Independent Human Rights Commission's annual report (2017) shows that violence against women in Afghanistan has increased by $8.6 \%$. The report states that 5575 cases of violence had been registered in 2017. This figure was 5132 in 2016. Of the total recorded violence, more than 1,500 cases of physical violence, more than 360 cases of sexual violence, more than 1,800 verbal and psychological violence, more than 1,100 cases of economic violence and remaining violence have been reported in response to behaviors that are traditionally disgraceful. In the reported physical violence section, more than 1,200 cases of beatings, 10 incidents, 57 injuries, 45 forced labor, and 234 deaths were included. The Independent Human Rights Commission argues that the statistics do not show the full reality due to the extent of this problem, and many cases of violence against women are likely to remain hidden for reasons of custom and lack of security.

Given the above reasons, it is argued that one of the key factors of violence against women increase in Afghanistan is the shortage of sex education at Afghanistan's schools. For example, several studies echo that presenting guidance by the teachers about sexual attitudes and behaviors of students at schools will reduce the occurrence of sexual assaults and gender violence in society. Because girls and boys as teenagers will learn about their sexual attitudes at schools. In other words, sex education will help students how to tackle their sexual problems appropriately, how to respect their opposite sex's sexual characteristics and not to look at their opposite sex as a physical and biological object but as a human being (Bleakley, Hennessy, \& Fishbein, 2016; Raphael, 2015).

Since there is not any formal sex education at schools in Afghanistan to educate students about their sexual attitudes and behaviors, most of the Afghan teenagers and youths obtain information about sexual issues secretly via the internet or friends. The Afghan Institute for Strategic Studies survey (2018) projects that this kind of approach toward knowing about sexual matters leads to watching porn movies that eventually result in porn addiction. Moreover, researchers believe that the lack of education at schools and the shortage of proper education of parents regarding sexual attitudes and behaviors of youths may create serious cultural and social problems for the health of the entire society. They argue that embedding the topic of sex education in the school curriculum can acquaint the children from the stage of childhood to sexual issues. The existing of sex education in school curriculum help teenagers not to feel shy talking about their sexual problems and needs in families, among their friends, or referring to a doctor because of their sexual problems. Furthermore, addressing sex education in an integrated education system may provide information for children and adolescents that won't provoke them toward inappropriate solving their sexual needs. Additionally, providing sex education through schools can help students not to look for other misleading channels for obtaining information about their sexual attitudes and behaviors (D.B. Kirby, 2008; Kirby \& Laris, 2009). 


\section{The Taboo of Sex Conversation in Afghan Society}

Traditional values that may restrict access to knowledge about sexual attitudes and behaviors might be the main barriers on debating regarding sexual issues among the families and youths in traditional societies (Heinemann, Atallah, \& Rosenbaum, 2016). In Afghanistan, there are many reasons why parents don't educate their children about sexual issues. First, only 31.741 percent of Afghan adults aged 15 and above are literate that is why most of the parents are not aware of the sexual issues due to not being able to read regarding sexual topics (The World Bank, 2011). Second, because of the cultural norms and traditions in Afghanistan, parents feel shy and discomfortable of conversing about sexual issues with their progenies thus they have a negative attitude to sexual attitudes and behaviors. Third, most of the parents in Afghanistan feel that if they talk about sexual issues with their children, the respect between them and their children is broken, thus, they neither want nor can to talk about sexual matters with their progenies (Afghan Institute for Strategic Studies Survey, June 2018).

Lack of information about sexual attitudes and behaviors often lead to misconceptions about sexual issues. This ignorance usually manifests itself in the form of shameful, impolite, and culturally abnormal conversation among the families in Afghanistan. Dr. Haidari Nasab, a psychological researcher (2017), believes that the question of how to answer children's inquiries about sexual attitudes and behaviors is a cultural issue. It depends on the culture of each community and the family how to respond and to get acquainted with sexual issues. He argues that the crucial point is that parents and teachers step by step should acquaint teens and adolescents with sexual attitudes and behaviors. Sexual information provided to a 3-year-old child is very different from that of a 13-year-old child. On the other hand, the lack of awareness and refusal to answer of puberty and sexual questions can provoke the curiosity of the newly-raised teenager, therefore, the family is the most important social elements that should give enough information and guidance to their teens in this respect.

In Afghanistan, since there is no formal sex education at school, and parents are not talking about sexual attitudes and behaviors with their progenies either, there is a risk that Afghan youths may become familiar inappropriately with sexual issues out of the home. Studies hold that educating teens and adolescents about sexual issues by parents and schools is a safe and healthy way. While gaining information about sexual needs and issues via friends and Internet may provoke teens and adolescents to commit sexual violence, rape, teasing their opposite sex in the society, and other abnormal deeds (Bleakley, Hennessy, Fishbein, \& Jordan; Kanuga \& Rosenfeld, 2004).

\section{CONCLUSION AND RECOMMENDATIONS FOR POLICY IMPLICATIONS}

Providing information on sex-related issues with regard to the age of young people accompanying family and religious values by parents and school counselors can play a crucial role in preventing the risks of sexual health of youths. Many parents, school counselors and teachers in Afghanistan lack the skills and information required in this regard, and sometimes their incorrect responses and lack of communication skills cause children to not come across their questions and often getting wrong and misleading information from your friends. The followings are some of the recommendations for responsible entities, families and other relevant bodies to address the issues related to sexual health of youths.

First, as schools are the main hubs of education for children, scholars are in this belief that school teachers should instruct the students that sexuality is a natural, normal, and healthy part of life. They 
should provide value-based education and offer students the opportunity to explore and define their individual values as well as the values of their families and communities. The discussion between teachers and students should include a wide variety of sexuality-related topics, such as human development, relationships, interpersonal skills, sexual expression, sexual health, society, and culture. The conversation should be based on accurate and factual information. Further, there are also many misconceptions about sexual issues originated during the childhood and adolescence period, and affect the sexual performance of youths in their adulthood, so sexual health education should be tailored as per the age of children and adolescents.

Second, since most of the families in Afghanistan, particularly in the countryside, don't have information about their sexual attitudes and behaviors, Ministry of Education in collaboration with Ministry of Public Health through school administrators should start public awareness campaigns in this regard. These campaigns should be held at schools and mosques. The campaigners should discuss the importance of knowing sexual attitudes and behaviors with the local people. They should tell the families that having information about sexual issues is not shameful and bad culturally and socially, but very vital and important for the health and social safety of their families and communities. Because, it is necessary for the parents and teachers, first of all, to receive the appropriate information for instructing teens, and then they can answer their questions related to sexual attitudes and behaviors.

It should be noted that information that is not associated with the transfer of values, has harmful effects on youths' social attitudes and behaviors (Parsi Teb Magazine, 2014). Therefore, parents should be equipped with information and communication skills about sexual health, so that they can, when needed, properly answer the questions of their children by transmitting values and keeping their children in a safe condition.

Finally, parents and teachers should create a sincere and faithful relationship with children in conversing with them regarding sexuality and sexual issues. Because as long as there is no trust between parents and teachers, teens and adolescents can't share their sexual problems and issues with them. Doing so, parents and teachers can reduce the risk of referring teens and adolescents to illegal and inappropriate channels for seeking the answers to their questions related to sexual attitudes.

\section{References}

Afghanistan's Independent Human Rights Commission. (2017). Annual report. Retrieved from http://www.aihrc.org.af/media/files/Anual \%20repor1395t.pdf

Afghanistan Independent Human Rights Commission. (June 20, 2018). Afghanistan human rights situation in the fiscal year 1396. Retrieved from https://www.aihrc.org.af/home/research_report/ 7450

Afghan Institute for Strategic Studies. (June 2018). Transition to adulthood; sexual attitudes and behaviors of youth in Afghanistan. Retrieved from http://www.aiss.af/assets/aiss_publication/

Sexual_Attitudes_and_Behaviors_of_Youth_in_Afgh anistan_(Farsi).pdf

BBC. (June 29, 2018). New research in Afghanistan: from masturbation to homosexuality. Retrieved from http://www.bbc.com/persian/afghanistan-44561628

Bleakley, A., Hennessy, M., \& Fishbein, M. (2006). Public opinion on sex education in US schools. Archives of Pediatrics \& Adolescent Medicine, 160(11), 1151-1156. 
Bleakley, A., Hennessy, M., Fishbein, M., \& Jordan, A. (2009). How sources of sexual information relate to adolescents' beliefs about sex. American journal of health behavior, 33(1), 37-48.

Compilation, D. o., \& Translation. (2003). Curriculum Framework Afghanistan. In: Ministry of Education Kabul, Afghanistan.

Heinemann, J., Atallah, S., \& Rosenbaum, T. (2016). The impact of culture and ethnicity on sexuality and sexual function. Current Sexual Health Reports, 8(3), 144-150.

Horizon News Agency. (Oct. 23, 2017). For the first time, gender issues are discussed in Afghanistan. Retrieved from http://www.ufuqnews.com/archives/ 44900

Kanuga, M., \& Rosenfeld, W. D. (2004). Adolescent sexuality and the internet: the good, the bad, and the URL. Journal of Pediatric and Adolescent Gynecology, 17(2), 117-124.

Kirby, D., \& Laris, B. (2009). Effective curriculumbased sex and STD/HIV education programs for adolescents. Child Development Perspectives, 3(1), 21-29.

Kirby, D. B. (2008). The impact of abstinence and comprehensive sex and STD/HIV education programs on adolescent sexual behavior. Sexuality Research \& Social Policy, 5(3), 18.

Marturana, A. (Oct. 26, 2016). 7 thins people get wrong about the hymen. Retrieved from https:// www.self.com/story/the-hymen-what-people-getwrong

Nasab. H. (2017). Sex education. Retrieved from http://www.pzf.ir/articles/problems/ sex education
Niazi, Z. (Oct. 30, 2016). Setting up sexual advocacy centers for young Afghans. Retrieved from http:// www.bbc.com/persian/afghanistan-37814994

Parsi Teb Magazine. (2014) Why is sexual education necessary? Retrieved from https://fa.parsiteb.com

Raphael, D. (2015). The Effect of Sexual Education on Sexual Assault Prevention.

Shayegan, E. (2014). The invisible trauma in Afghanistan. Global Journal of Arts Humanities and Social Sciences, 2(5), 13-23.

The World Bank. (2011). United Nations Educational, Scientific, and Cultural Organization (UNESCO) Institute for Statistics. Retrieved from https:// data.worldbank.org/indicator/SE.ADT.LITR.ZS? locations $=\mathrm{AF}$ 